\title{
ТЕХНОЛОГІЧНІ ТА КОНСТРУКТИВНІ МЕТОДИ ЗНИЖЕННЯ РІВНЯ НИЗЬКОЧАСТОТНОГО ШУМУ В n-p-n ТРАНЗИСТОРАХ
}

В статті приведено аналіз складових низькочастотного шуму біполярних транзисторів, розроблені конструктивні та технологічні методи, яки дозволяють зменшити величину низькочастотного шуму і приведено дані коефічієнту шуму на експериментальних зразках транзисторів. Біполярні малошумні транзистори використовують в вхідних каскадах та каскадах попереднього підсилення малих вхідних сигналів в електронної апаратурі різноманітного призначення, щяо зменшує перекручування сигналів $i$ збільшує чутливість на вході. Чім менш рівень шуму транзисторів, яки використовуються, тим вище якість електронної апаратури. Крім загальновідомих складових низькочастотного шуму, яки розраховуються за відомими вираженнями, в статті приведено додаткові складові шуму, яки з-за випадкових факторів в кожному конкретному випадку, не піддаються розрахунку. Аналіз всіх складових шуму в біполярному транзисторі показав, щчо можливо зменшити рівень шумів як конструктивними для одних складових шуму, так й технологічними методами для інших складових. В процесі роботи були розроблені конструкція и технологія кремнієвого планарного п-р-n транзистора зі зниженим рівнем низькочастотного шуму. Виготовлення експериментальних зразків транзисторів та вимірювання їх електричних параметрів проводилися на стандартному устаткуванні, яке використовується для виготовлення малошумних транзисторів серії КТЗ102, яки взято за аналог. Для зменшення рівня шуму в конструктивному плані доцільно використовувати геометрію емітерів в вигляд $i$ полос, а в технологічному плані доцільно формувати базу транзистора малою дозою домішку, але зі збільшеною товщчною бази, а також під базові контакти застосовувати додаткові дифузійні шари ртипу провідності з підвищеною величиною поверховій концентрації. Середні значення коефіцієнту низькочастотного шуму на експериментальних транзисторах отримано приблизно на $30 \%$ менш, ніж у аналогічних по електричним параметрам і характеристикам транзисторів серї КТЗ102, щ⿻ доказує можливість зменшення низькочастотних шумів як конструктивними, так й технологічними методами.

Ключові слова: транзистор, низькочастотний шум.

А.Н. ФРОЛОВ

Национальный университет кораблестроения имени адмирала Макарова ORCID: 0000-0003-2186-9488

С.Р.СЕЛИВЕРСТОВА

Херсонская государственная морская академия ORCID: 0000-0003-1015-1593

О.Л. КИРИЛЛОВ

Национальный университет кораблестроения имени адмирала Макарова ORCID: 0000-0002-8021-6340

\section{ТЕХНОЛОГИЧЕСКИЕ И КОНСТРУКТИВНЫЕ МЕТОДЫ ПОНИЖЕНИЯ УРОВНЯ НИЗКОЧАСТОТНОГО ШУМА В n-p-n ТРАНЗИСТОРАХ}

В статье приведен анализ составляющих низкочастотного шума биполярных транзисторов, разработаны конструктивные и технологические методы, которые позволяют уменьиить величину низкочастотного шума, и приведень данные коэффициента шума на экспериментальных образиах транзисторов. Биполярные малошумящче транзисторы применяют во входньх каскадах и каскадах предварительного усиления малых входных сигналов в электронной аппаратуре различного назначения, что уменьшает искажения сигнала на выходе и увеличивает чувствительность на входе. Чем меньше уровень иума применяемых транзисторов, тем выше качество электронной аппаратуры. Кроме общеизвестных составляющих низкочастотного иума, которые рассчитываются по известным выражениям, в статье приводятся дополнительные составляющие шума, которые, из-за случайных 
факторов в каждом конкретном случае, не поддаются расчету. Анализ всех составляюших шума в биполярном транзисторе показал, что можно уменьшить уровень шумов как конструктивными для одних составляющих шума, так и технологическими методами для других составляющих. В процессе работы были разработаны конструкция и технология биполярного кремниевого планарного $n$-p- $n$ транзистора с пониженным уровнем низкочастотного шума. Изготовление экспериментальных образияов и измерение их электрических параметров проводилось на стандартном оборудовании, применяемом для изготовления малошумящих кремниевых транзисторов серии КТЗ102, принятых за аналог. Для уменьшения уровня шума в конструктивном плане иелесообразно применять полосковую геометрию эмиттеров, а в технологическом плане целесообразно формировать базу транзистора малой дозой примеси, но с увеличенной толщчиной базы, а также под базовые контакты применять дополнительные диффузионные слои р-типа проводимости с увеличенной величиной поверхностной концентрации. Усредненные значения коэффициента низкочастотного иума на экспериментальных транзисторах получены примерно на 30\% меньше, чем у аналогичных по электрическим параметрам и характеристикам транзисторов серии КТ3102, что доказывает возможность уменьшения низкочастотных шумов как конструктивными, так и технологическими методами.

Ключевые слова: транзистор, низкочастотный шум.

A.N. FROLOV

National University of Shipbuilding named after Admiral Makarov ORCID: 0000-0003-2186-9488

S.R. SELIVERSTOVA

Kherson State Maritime Academy

ORCID: 0000-0003-1015-1593

O.L. KIRILLOV

National University of Shipbuilding named after Admiral Makarov

ORCID: 0000-0002-8021-6340

\section{TECHNOLOGICAL AND CONSTRUCTIVE METHODS FOR REDUCING THE LEVEL OF LOW-FREQUENCY NOISE IN n-p-n TRANSISTORS}

The article provides an analysis of the components of the low-frequency noise of bipolar transistors, developed constructive and technological methods that allow to reduce the amount of low-frequency noise, and provide data on the noise figure on experimental samples of transistors. Bipolar low-noise transistors are used in the input stages and stages of preliminary amplification of small input signals in electronic equipment for various purposes, which reduces signal distortion at the output and increases the sensitivity at the input. The lower the noise level of the used transistors, the higher the quality of the electronic equipment. In addition to the well-known components of low-frequency noise, which are calculated according to known expressions, the article contains additional noise components that, due to random factors in each specific case, cannot be calculated. Analysis of all noise components in a bipolar transistor has shown that it is possible to reduce the noise level both by constructive for some noise components and by technological methods for other components. In the process of work, the design and technology of a bipolar silicon planar n-p-n transistor with a low level of low-frequency noise were developed. The manufacture of experimental samples and the measurement of their electrical parameters were carried out on standard equipment used for the manufacture of low-noise silicon transistors of the KT3102 series, taken as an analogue. To reduce the noise level in the constructive sense, it is advisable to use the strip geometry of the emitters, and in the technological plan, it is advisable to form the base of the transistor with a small dose of impurity, but with an increased base thickness, and also to use additional diffusion layers of p-type conductivity with an increased value of the surface concentration under the base contacts. The averaged values of the low-frequency noise factor on the experimental transistors were obtained by about $30 \%$ less than those of the KT3102 series transistors similar in electrical parameters and characteristics, which proves the possibility of reducing low-frequency noise by both constructive and technological methods.

Keywords: transistor, low-frequency noise.

\section{Постановка проблеми}

Промисловістю різних країн випускається велика кількість універсальних транзисторів. Особливу групу серед них складають малошумливі транзистори. Вони застосовуються в малошумящей аналоговій техніці, як правило, у вхідних каскадах і каскадах попереднього посилення. Однак, і при цифровій обробці інформації при слабких вхідних сигналах необхідно застосовувати транзистори з малим рівнем сигналів. Поява власних шумів застосовуваних транзисторів у вхідних каскадах зменшує чутливість приладу i призводить до викривлень. Тому, виникає необхідність в малошумних напівпровідникових приладах, в тому числі, транзисторах. 3 самого початку появи транзисторів для зниження рівня шумів постійно проводяться дослідження різних видів шумів і їх джерел $[1,2]$. Після початку промислового виробництва 
біполярних транзисторів, частину з них випускали як малошумливі, - з вимірюванням рівня шумів [3,4]. У міру розвитку технології рівні низькочастотних шумів зменшувалися, що показано даними в таблиці 1.

Показники зменшення рівня низькочастотного шуму біполярних транзисторів

\begin{tabular}{|c|c|c|c|c|c|}
\hline № & $\begin{array}{c}\text { Тип біполярних } \\
\text { транзисторів, }\end{array}$ & Матеріал & Технологія & $\begin{array}{c}\text { Максимальний струм } \\
\text { колектора, мА }\end{array}$ & $\begin{array}{c}\mathrm{K}_{ш}, \partial Б, \\
\text { не больше }\end{array}$ \\
\hline 1 & МП28, $\quad$ p-n-p & Германій & Сплавна & 6 & 5 \\
\hline 2 & МП36А, n-p-n & Германій & Сплавна & 20 & 12 \\
\hline 3 & МПЗ9Б, $p-n-p$ & Германій & Сплавна & 20 & 12 \\
\hline 4 & MП101A, n-p-n & Кремній & Сплавна & 20 & 15 \\
\hline 5 & BC70J, BCX71K & Кремній & Планарна & 100 & 6 \\
\hline 6 & BCW60B, (C, D) & Кремній & Планарна & 100 & 6 \\
\hline 7 & KT3102A $(Б, B, \Gamma)$ & Кремній & Планарна & 100 & 4 \\
\hline 8 & BC849, BC859 & Кремній & Планарна & 100 & 4 \\
\hline
\end{tabular}

3 даних таблиці 1 видно, що:

1. Електронна промисловість різних країн проводила i проводить випуск малошумних транзисторів.

2. Чим менше допустимий максимальний струм колектора при однаковій технології, тим менше коефіцієнт шуму, що видно за даними германієвих транзисторів.

3. Рівень шумів транзисторів одного типу провідності в міру розвитку технології зменшується.

4. У кремнієвих транзисторів, виготовлених за планарною технологією, рівень шумів менше ніж у германієвих транзисторів, виготовлених за сплавною технологією.

Аналіз останніх досліджень і публікацій

Як показано в [5] для зменшення низькочастотних шумів можуть бути застосовані зміни в конструкції напівпровідникових приладів і в технології їх виготовлення.

Низькочастотні шуми в біполярних транзисторах складаються з декількох складових [6,7]: - 3 теплових шумів в розподіленому опорі бази, з дробових шумів струмів, які протікають через p-n переходи і з рекомбінаційних шумів, які діляться на поверхневі рекомбінаційні шуми і на рекомбінаційні шуми в об’ємі. Вочевидь, що крім цих складових існують і ще кілька причин появи низькочастотного шуму, наприклад, пов'язані з нерівномірністю дифузійного фронту на p-n переходах.

1. Перша складова шуму - це теплові шуми, які визначаються напругою шумів $\left(u_{T . b}\right)$ на опорі бази і описуються формулою Найквіста:

$$
\bar{u}_{T . Б}^{2}=4 k T \cdot r_{\sigma} \cdot \Delta f
$$

де $\quad k$-постійна Больцмана;

$T$ - температура;

$\Delta f$ - діапазон частот;

$r_{\sigma}$ - опір бази.

В даному випадку при вимірюванні шумів постійними величинами $\epsilon \mathrm{k}, \mathrm{T}$ i $\Delta$ f. А єдиною величиною, на яку можна вплинути зміною конструкції або технології виготовлення $\epsilon$ опір бази транзистора - $\mathrm{r}_{б}$. Для зменшення цієї складової шуму необхідно зменшувати опір бази.

2. Друга складова шумів в транзисторах - це дробові шуми, які виникають через флуктуацій струмів, що протікають через p-n переходи. Струм дробового шуму визначається за формулою:

$$
\bar{i}_{Д}^{2}=2 e \cdot I \cdot \Delta f
$$

де

I - струм, що протікає через транзистор в режимі вимірювання шумів;

е - заряд електрона.

При вимірі шумів в заданих режимах ці величини є постійними. Тому дана складова шуму не може бути змінена ні технологічним, ні конструктивним способом.

3. Поверхневі рекомбінаційні шуми в своїй основі виникають через процеси рекомбінації дірок 3 електронами на поверхні напівпровідника. Третя складова шуму - це ток поверхневого рекомбінаційного шуму, який визначається виразом:

$$
\bar{i}_{p}^{2}=A \cdot \frac{\Delta f}{f}
$$


де

$f$ - частота;

$A$ - коэфіцієнт пропорційності.

Для зменшення цієї складової шуму необхідно збільшувати граничну частоту транзистора i зменшувати величину $A$. Очевидно, що рекомбінаційні процеси на поверхні пов'язані з струмами витоку $I_{\text {КБ }}$ і IЭБо. Чим менше ці струми, тим менше процесів рекомбінації, як на поверхні, так в обсязі транзистора.

4. Об'ємні рекомбінаційні шуми виникають в p-n переходах емітера $\left(i_{p . \ni}\right)$ і колектора $\left(i_{p . \kappa}\right)$, а також в обсягах бази і колектора через дефекти кристалічної гратки. Четверта складова шумів в транзисторах це рекомбінаційний ток шуму в області емітера, який визначається виразом:

$$
\bar{i}_{p . \ni}^{2}=A_{\ni} \cdot I_{\ni} \cdot \frac{\Delta f}{f} ;
$$

де $\quad I_{\ni}$ струм через емітерний р-n перехід в режимі вимірювання шумів;

$A_{\ni}$ - коефіцієнт, пов'язаний з інтенсивністю процесів рекомбінації електронів і дірок на емітерному p-n переході.

Так як інтенсивність процесів рекомбінації дірок і електронів у емітера пропорційна концентрації, то для зменшення цієї складової шуму необхідно зменшувати концентрацію домішки на емітерний p-n

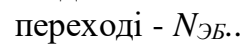

5. П'ята складова шуму - це рекомбінаційний струм шуму в області колекторного p-n переходу,

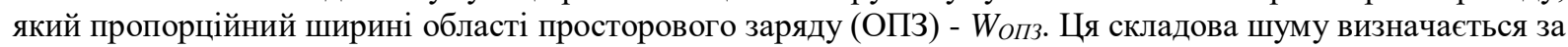
виразом:

$$
\bar{i}_{p . K}^{2}=A_{K} \cdot \sqrt{U_{K}} \cdot \frac{\Delta f}{f}
$$

де

$U_{K}$ - напруга на колекторі в режимі вимірювання шумів.

Для зменшення цієї складової шуму необхідно зменшувати ширину ОПЗ p-n переходу колекторбаза. Так як напруга на колекторі в заданих режимах вимірювання є величиною постійною, то для зменшення ширини ОПЗ необхідно збільшувати концентрацію домішки на колекторному p-n переході $N_{K Б}$, тобто застосовувати мінімально необхідне питомий опір епітаксійного шару.

6. Додатковими складовими шумів в транзисторах є дефекти кристалічної структури (шоста складова шуму). Чим менше дефектів, тим менше буде ця складова шуму транзистора.

7. Крім того, можлива поява і ще однієї складової шуму (сьома складова), яка пов'язана 3 нерівномірністю дифузійних фронтів емітерного і колекторного p-n переходів. Вид нерівномірності дифузійних фронтів показаний на рисунку 1.

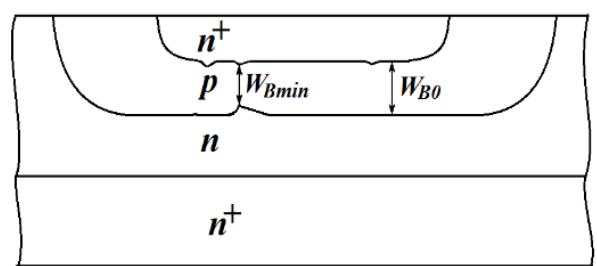

$\triangle W_{B}=W_{B 0}-W_{B \min }$<smiles>C1CCC2(CC1)CCCC2</smiles>

Рис.1. Структура n-p-n транзистора $з$ нерівномірністю дифузійних шарів бази та емітера

Нерівномірність дифузійних фронтів призводить до появи ділянок з меншою товщиною бази. У цих ділянках з'являється підвищена щільність струмів, що призводить до збільшення температури даної ділянки. Згідно формули (1) це призводить до підвищення величини $u_{T .5}$ i до збільшення рівня шумів транзистора. Чим менше відношення $\Delta W_{B} / W_{B 0}$, тим менше щільність струму на ділянках нерівномірності дифузійних фронтів. Це відношення можна зменшити збільшенням величини $W_{B 0}$ - товщини бази по металургійним межам p-n переходів.

\section{Формулювання мети дослідження}

Основне завдання - визначити основні напрямки зменшення низькочастотних шумів в дрейфових n-p-n транзисторах конструктивними і технологічними методами на основі аналізу всіх складових низькочастотного шуму в транзисторах і створити структуру малошумящего транзистора зі зменшеним рівнем шумів і технологію його виготовлення. 


\section{Викладення основного матеріалу дослідження}

Як правило, малошумні транзистори представляють собою кремнієві планарні універсальні транзистори 3 напругою пробою до 100В. В якості експериментальної структури був обраний транзистор з електричними параметрами і характеристиками аналогічними малошумним транзисторам серії КТ3102. Для виготовлення транзисторів була застосована одношарова кремнієва епітаксіальна структура тіпономіналом:

$$
76 \frac{10 К Э Ф 2,7}{400 Э К Э С 0,01}
$$

де: 76 - діаметр підкладинки, мм;

10 - товщина епітаксійного шару n-типу провідності, мкм;

2,7 - питомий опір епітаксійного шару, Ом·см;

400 - товщина підкладки n-типу провідності, мкм.

0,01- питомий опір підкладки, Ом·см;

КЭФ - кремній, електронний, легований фосфором;

ЭКЭС - епітаксіальний кремній, електронний, легований сурмою.

Після хімічної обробки, стандартного окислення i першої фотолітографії на пластинах формувалися базові області в два етапи. На першому етапі проводилося іонне впровадження бору на установках типу «Везувій» малою дозою бору - 4 мкКл/см². Потім, проводився перерозподіл базової домішки (разгонка) в термодіффузіонних печах при температурі $1180^{\circ} \mathrm{C}$ в парогазовому середовищі: - 5 хв. (Сухий кисень) + 15хв. (Пари води з 1\% соляною кислотою) + 90хв. (Сухий кисень).

Мала доза домішки, що впроваджена в базу, і висока температура, при дифузії бору в базу, дозволяють усунути або істотно зменшити число радіаційних дефектів, що виникають після іонного впровадження. Додатково до цього, чим менше доза домішки, тим менше кількість дефектів кристалічної структури, що виникають після дифузії домішки [8], які також можуть викликати флуктуації струмів в базі транзистора. Таким чином, ця (сьома) складова шумів транзистора зменшується.

Крім того, при формуванні базової області малою дозою колекторний p-n перехід виходить не ступінчастим (різким), а наближається до лінійного (плавного), що дозволяє зменшити питомий опір епітаксійного шару при збереженні напруги пробою. При цьому збільшена концентрація домішки на колекторному p-n переході призводить до зменшення ширини ОПЗ цього переходу і до зменшення рекомбінаційного струму $i_{p . K}$. Однак при малій дозі поверхнева концентрація домішки в базі виходить малою, що може створити на контакті металу до базових областей переходу Шотткі, що має випрямними властивостями. Крім того, мала поверхнева концентрація, при наявності рухомих і нерухомих позитивних зарядів в шарах захисного оксиду кремнію і на кордоні «кремній - оксид кремнію» може привести до створення инверсионного шару n-типу провідності i до замикання емітера 3 колектором в n-p-n транзисторі.

Тому, на наступному етапі виготовлення транзисторів формувалися додаткові області під базові контакти після другої фотолітографії і дифузії бору в дві стадії. На першій стадії (загонкою) проводилося диффузійне впровадження домішки бору в термодіфузійній печі для отримання поверхневого опору $\mathrm{R}_{\mathrm{S}}=1100 \mathrm{M} / \square$. Значення поверхневого опору областей р-типу провідності вимірювалися 4-х зондовим методом. Для подальшого зменшення величини $\mathrm{r}_{\sigma}$ поверхневий опір необхідно формувати мінімально можливим, але так, щоб значення напруги пробою p-n переходу емітер-база не стали менш допустимого значення.

Друга стадія (разгонка) для перерозподілу домішки проводилася в термодіффузіонного печах при температурі $1150^{\circ} \mathrm{C}$ з одночасним окисленням в перебігу - 65 хв. Отримані області з високою поверхневою концентрацією домішки під базові контакти повністю оточували емітери для виключення інверсних шарів, як показано на рисунку 2. А низькі значення поверхневого опору областей під базові контакти дозволяють зменшити опір від базового контакту до краю емітера, що зменшує одну 3 основних складових низькочастотних шумів за рахунок зменшення величини $r_{\sigma}$ в формулі (1).

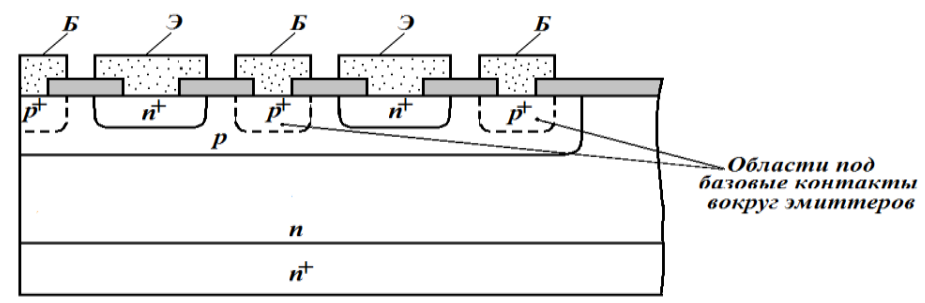

Рис.2. Фрагмент структури n-p-n транзистора 3 додатковими областями p + -типу під контактами до бази. 
Потім, слідували технологічні операції: фотолітографія під емітери, дифузія фосфору при температурі $1040^{\circ} \mathrm{C}$ протягом $23-25$ хв., фотолітографія під контактні вікна, вимір електричних параметрів на тестових елементах. Електричні параметри і характеристики тестових структур вимірювалися на вимірнику параметрів напівпровідникових приладів - установці Л2-56.

Для отримання експериментальних зразків транзисторів з різними коефіцієнтами підсилення був застосований процес доразгонки фосфору при температурі $850^{\circ} \mathrm{C}$ для різних пластин протягом від 15 хв. до 45 хв. Після чергового вимірювання електричних параметрів транзисторів проводилося вакуумне напилення алюмінію, фотолітографія по алюмінію, відпал алюмінію при температурі $510^{\circ} \mathrm{C}$ протягом 15 хв. в неокісленій атмосфері і вимірювання електричних параметрів транзисторів на кристалах.

Розкид коефіцієнтів посилення транзисторів по кожній пластині становив $\pm(6-9) \%$, рівень струмів витоку колекторного p-n переходу $\left(I_{\kappa Б 0}\right)$ не перевищував 0,001 мкА. Для збірки в корпус були відібрані пластини $з$ величинами коефіцієнтів посилення $(140 \pm 11)$ од., $(292 \pm 20)$ од., $(675 \pm 35)$ од., Тобто з різною товщиною бази. Транзистори були зібрані в корпус КТ-46 (SOT-23). Після відбраковування по електричним параметрам (напруги пробою, струми витоку, коефіцієнти посилення, гранична частота) для досліджень було відібрано по 10 шт. транзисторів, отриманих з різних пластин методом випадкового відбору. Значення граничної частоти на експериментальних зразках склали (420-450) МГц, що вище, ніж у аналогів, - транзисторів серії КТ3102 - (309-321) МГц. Вимірювання коефіцієнта низькочастотного шуму експериментальних зразків проводилося на стандартному обладнанні методом безпосереднього вимірювання одночасно з вимірюванням шумів біполярних транзисторів серії КТ3102. Також на цих транзисторах проводилось вимірювання коефіцієнтів посилення. Результати вимірювань і порівняльні параметри транзисторів КТ3102 наведені в таблиці 2.

Таблиця 2

Дані вимірювань коефіцієнтів посилення і низькочастотних шумів

\begin{tabular}{|c|c|c|c|c|c|c|c|c|}
\hline \multirow{3}{*}{ № } & \multicolumn{6}{|c|}{ Експериментальні транзистори } & \multirow{2}{*}{\multicolumn{2}{|c|}{ KT3102 }} \\
\hline & \multicolumn{2}{|c|}{ 1-а група } & \multicolumn{2}{|c|}{ 2-a група } & \multicolumn{2}{|c|}{ 3-а група } & & \\
\hline & $h_{21 \text { э, }}$ ед. & $K_{\mathrm{II}}, \partial \sigma$ & $h_{219}$, ед. & $K_{\mathrm{m}}, \partial \sigma$ & $h_{213}$, ед. & $K_{\mathrm{m}}, \partial \sigma$ & 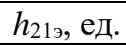 & $K_{\mathrm{m}}, \partial \sigma$ \\
\hline 1 & 135 & 2,5 & 295 & 2,5 & 690 & 2,4 & 530 & 3,6 \\
\hline 2 & 142 & 2,4 & 300 & 2,5 & 675 & 2,5 & 575 & 3,5 \\
\hline 3 & 145 & 2,6 & 293 & 2,6 & 695 & 2,5 & 565 & 3,3 \\
\hline 4 & 151 & 2,4 & 275 & 2,4 & 655 & 2,4 & 615 & 3,6 \\
\hline 5 & 150 & 2,4 & 280 & 2,5 & 655 & 2,5 & 610 & 3,6 \\
\hline 6 & 137 & 2,5 & 290 & 2,4 & 670 & 2,4 & 540 & 3,7 \\
\hline 7 & 130 & 2,6 & 305 & 2,5 & 685 & 2,6 & 600 & 3,6 \\
\hline 8 & 135 & 2,5 & 307 & 2,4 & 670 & 2,4 & 560 & 3,5 \\
\hline 9 & 135 & 2,4 & 280 & 2,5 & 675 & 2,4 & 545 & 3,7 \\
\hline 10 & 140 & 2,4 & 295 & 2,4 & 680 & 2,5 & 560 & 3,7 \\
\hline Середні & 140 & 2,47 & 292 & 2,47 & 675 & 2,46 & 570 & 3,58 \\
\hline
\end{tabular}

Як видно 3 даних таблиці 2 рівень низькочастотного шуму на експериментальних зразках приблизно на $1 / 3$ менше, ніж у аналогів КТ 3102 . Також, експериментальні зразки мали вищу граничну частоту - (470-480) МГц проти (308-315) МГц у КТ3102.

Крім того, не виявлено явна залежність коефіцієнта шуму від коефіцієнта посилення транзистора, що може бути пов'язано з малою кількістю експериментальних зразків.

\section{Висновки}

1. В результаті дослідження отримана структура високочастотного кремнієвого універсального дрейфового n-p-n транзистора зі зменшеним на $30 \%$ рівнем низькочастотних шумів в порівнянні 3 аналогом КТЗ 3102.

2. Застосування полоскової конструкції (топології) транзистора і додаткової дифузії під базові контакти дозволяють зменшити величину $r_{\sigma}$, що призводить до зменшення складової шуму - напруги шумів $u_{T .5}$.

3. Застосування зменшеною дози домішки для створення бази транзистора дозволяє:

- сформувати колекторний лінійний p-n перехід замість ступеневої, що призводить до можливості збільшити концентрацію домішки в епітаксиальні шарі при збереженні напруги лавинного пробою. А це зменшує ширину ОПЗ колекторного p-n переходу і зменшує складову шуму, - рекомбінаційний струм шуму в області колекторного $\mathrm{p}-\mathrm{n}$ переходу $i_{p . K}$;

- зменшити концентрацію домішки на емітерному p-n переході, що призводить до зменшення складової шуму, - рекомбінаційного струму шуму в області емітера - $i_{p . \text {; }}$

- зменшити кількість дефектів кристалічної структури, що зменшує додаткові складові шуму; 
- призводить до необхідності формувати базу з більшою товщиною, що, при появі нерівномірності дифузійних фронтів, призводить до зменшення щільності струму в аномальних точках і зменшує додаткові величини в складовій шуму - напрузі шумів $u_{T .5}$.

\section{Список використаної літератури}

1. Bu S.T., Huang D.M., Jiao G.F., Yu H.Y., Ming-Fu Li. Low frequency noise in tunneling field effect transistor. Solid State Electronics. 2017. Vol. 137. P.95-101.

2. Slatter J. Full direct low frequency noise characterization of GaAs heterojunction bipolar transistor. Solid State Electronics. 2005. Vol. 49, № 8. P.1361-1369.

3. Полупроводниковые приборы. Транзисторы: справочник / Горюнов Н.Н., В.Л.Аронов, А.В.Баюков. Москва: Энергоатомиздат, 1985. 904 с.

4. Md Mazhar Ul Hoque, Zeynep Çelik-Butler, Samuel Martin, Chris Knorr, Constantin Bulucea. Dependence of low frequency noise in SiGe heterojunction bipolar transistors on the dimensional and structural features of extrinsic regions. Solid State Electronics. 2005. Vol. 50, № 7-8. P.1430-1439.

5. Simoen F., Mercha A., Claeys C., Lukyanchicova N.. Low frequency noise in silicon on insulated device and technologies. Solid State Electronics. 2006. Vol. 51, № 1.- P.16 -37.

6. Физика полупроводниковых приборов: в 2-х книгах / гл.ред. Зи С. М.: Мир, 1984. Т.1. 456 с.

7. Самойлов Н.А., Фролов А.Н., Шутов С.В. Влияние профиля легирования на пробивные напряжения коллекторного перехода в планарных n-p-n транзисторах. Журнал технической физики. 1998. №10, т.68. - С.136 -137.

\section{Referenses}

1. Bu S.T., Huang D.M., Jiao G.F., Yu H.Y., Ming-Fu Li. Low frequency noise in tunneling field effect transistor. Solid State Electronics. 2017. Vol. 137. P.95-101.

2. Slatter J. Full direct low frequency noise characterization of GaAs heterojunction bipolar transistor. Solid State Electronics. 2005. Vol. 49, № 8. P.1361-1369.

3. Semiconductor devices. Transistors: reference book / Goryunov N.N., V.L. Aronov, A.V. Bayukov. Moscow: Energoatomizdat, 1985. 904 p.

4. Md Mazhar Ul Hoque, Zeynep Çelik-Butler, Samuel Martin, Chris Knorr, Constantin Bulucea. Dependence of low frequency noise in SiGe heterojunction bipolar transistors on the dimensional and structural features of extrinsic regions. Solid State Electronics. 2005. Vol. 50, № 7-8. P.1430-1439.

5. Simoen F., Mercha A., Claeys C., Lukyanchicova N.. Low frequency noise in silicon on insulated device and technologies. Solid State Electronics. 2006. Vol. 51, № 1.- P.16 -37.

6. Physics of semiconductor devices: in 2 books / Ch.ed. Zi S.M .: Mir, 1984.Vol. 1. 456 p.

7. Samoilov N.A., Frolov A.N., Shutov S.V. Influence of the doping profile on the breakdown voltages of the collector junction in planar n-p-n transistors. Technical Physics Journal. 1998, no. 10, v. 68, pp. 136 -137. 